\title{
External Environmental Analysis of Technical Systems for Establishing R\&D Strategies
}

\author{
Seung Hyun Kang ${ }^{1}$, Yong Won Song ${ }^{2}$, Jung Won Yeom ${ }^{3}$ \\ ${ }^{1}$ Researcher, Industry-Academic Cooperation Foundation, Korea Polytechnic University, Korea, \\ shkang@kpu.ac.kr \\ ${ }^{2}$ Professor, Nano \& Semiconductor Engineering Department, Korea Polytechnic University, Korea, \\ ywsong@kpu.ac.kr \\ ${ }^{3}$ Student, Nano \& Semiconductor Engineering Department, Korea Polytechnic University, Korea, \\ yeomjw0907@kpu.ac.kr
}

Corresponding author: Yong Won Song

\begin{abstract}
Analyzing the external environment of technical systems emerging from objective patterns of technical system evolution is essential for predicting future technological development and for establishing R\&D strategies. However, STEEP, a typical environmental analysis tool (involving social, technological, economic, environmental, and political aspects) and qualitative investigation method, is not easy for researchers in science, technology, and engineering to use effectively without having expertise in the relevant area. This study aims to develop a method that can be easily used by nonspecialist researchers in R\&D. To achieve this, the external environment was divided into the macro environment and the micro environment by applying multi-screens, a systematic analysis method of the theory of inventive problem solving (TRIZ). Specifically, macro environmental factors are defined as STEEP while micro environmental factors, which have a direct effect on the survival or success of a technical system, are defined as five supersystems based on Porter's five forces framework. For analyzing the macro environment, a wide range of the existing STEEP factors were systematically subcategorized around the key concepts. These concepts were defined according to the analytical purpose of market-oriented technology development and topic of analysis for each field of STEEP. Based on this classification system, the STEEP analysis template, a practical tool for macro environmental analysis, was developed to derive the core STEEP keywords. Similarly, a template for supersystem analysis was developed to analyze the relationship and influence of STEEP keywords on the five supersystems. This STEEP factors classification method and the templates are expected to provide a guideline for quickly and easily analyzing the influence of STEEP factors on a technical system.
\end{abstract}

Keywords: STEEP, Five Forces Analysis, TRIZ, Multi-screens, R\&D Strategy

\section{Introduction}

As technological progress is accelerating and product life cycles are decreasing in the era of the Fourth Industrial Revolution, objective prediction of future technology development is extremely important in R\&D planning centered on product development. Widely used prediction methods include Delphi, Text Mining, Analysis Hierarchy Process (AHP), and Technology Roadmaps. These methods, based on extensive data, including patents, surveys, and assessments of several experts from various fields, are not only costly and time-consuming, but also dependent on experts' decisions, which can be

Received: September 8, 2021; $1^{\text {st }}$ Review Result: October 22, 2021; $2^{\text {nd }}$ Review Result: December 11, 2021 Accepted: January 29, 2022 
subjective[1]. In an effort to address these limitations, researchers are attempting to apply technology evolution trends and the theory of inventive problem solving (translated as the abbreviation TRIZ), which was proposed by Russian scientist Genrich S. Altshuller[2], to further develop prediction technology. Since this prediction technique presents several potential future development directions for a given technical system, selecting the right direction is part of the R\&D planning and product development. The choice is made by considering various selection criteria, of which external environmental factors are most significant. In this study, an external environmental analysis focuses on the social, cultural, economic, and political factors and trends that influence the success and selection of technical systems in the market.

Tools commonly used to analyze the external environment, including STEEP (social, technological, economic, environmental, and political aspects), PEST (political, economic, social, and technological aspects), and PESTEL (political, economic, social, technological, environmental, and legal aspects), have the advantage of classifying the changing factors of enormous and complicated external environments in various categories. However, as qualitative basic investigation methods, they are generally used together with quantitative methods, including Delphi, big data analysis, and AHP, to predict future development in specific areas[3-6]. This means that external environmental analysis requires the involvement of many experts from various fields, and an enormous amount of money and time. Consequently, individual researchers or those from small and medium-sized companies, with limited resources, personnel, time, and budgets, find it difficult to take advantage of the external environmental analysis methods in $\mathrm{R} \& \mathrm{D}$ planning or product development.

Against this backdrop, this study aims to develop a method and a user-friendly tool that can be used to analyze the external environment, which influences the development of a technical system.

This study focused on STEEP analysis, one of the most commonly used tools for external environmental analysis. The goal is to develop a method that enables non-specialist researchers and engineers without expertise in environmental analysis to use STEEP analysis to aid R\&D planning and product development. To do so, key indicators were derived, and the relationship between the indicators and a specific technical system was analyzed based on the systematic method of TRIZ.

\section{Research Methodology}

\subsection{Main Tool in Systematic Thinking Method of TRIZ: Multi-screens System Operator}

The essence of the TRIZ method of systematic thinking is based on the analysis of a system from various perspectives; that is, the basic function, changes in time, components of the system (subsystems), and its relationship with external elements of the system (supersystems), providing a minimum of nine directions[7]. This is the first step in a systematic analysis. The Nine Screens System operator (also called as multi-screens), suggested by Altshuller, is used as a tool in this study, because it can be expanded to more than nine directions (screens) of thinking according to the research scope[8]. A systematic approach using the multi-screens system operator is shown in [Fig. 1]. In this figure, a tree system is presented at different system levels from the entire tree (system), to a leaf (subsystem), to a forest (supersystem), and so on, along with the same variants from the past, present, and future (line of evolution)[8].

In this study, the basic concept of the systematic analysis method of TRIZ is applied for the external environmental analysis of a technical system. The supersuper-systems of a given system are defined as macro environmental factors and the supersystems are defined as micro environmental factors directly related to the technical system. 


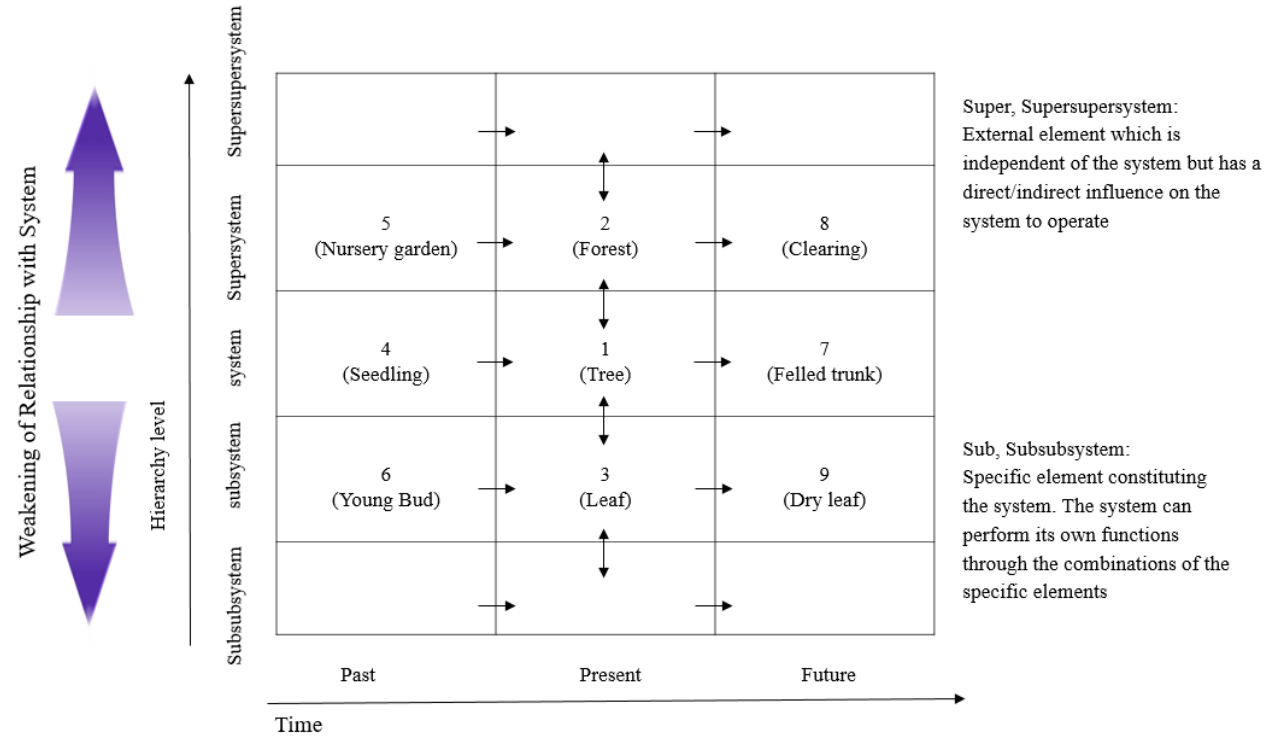

[Fig. 1] Tree Analysis Using the Multi-screens System Operator of TRIZ

\subsection{Supersuper-system Analysis: Macro Environmental Analysis Using STEEP Method}

STEEP analysis is used to analyze the main indicators in five areas-social, technological, economic, environmental, and political-to identify key trends in each area. The quality of the analysis relies on the amount and level of relevant data as well as the indicators[1]. The classification methods and indicators differ slightly depending on the organization. This study examines the indicators used by six organizations and researchers in the fields of business management, science and technology, and marketing. These indicators are largely divided into two categories: listing by area [1][9-11] and subcategorization by specific subject[12][13]. In the classification by area, researchers identify the main indicators for each area. However, there are many indicators, and most importantly, it is difficult for non-experts to reach a meaningful interpretation using the relevant indicators. In the classification by subject, it is relatively easy for non-experts to interpret the meaning of the indicators, but there are times when researchers have to find the indicators themselves. Take the example of demographic indicators in the social area. In the first classification (listing by area), the indicators are presented as birth and death rates, and percentage of the population in economic and social segments[9]. In the second classification (sub-categorization by specific subject), demographic indicators are specified under the category of factors that influence demand and supply[12], where specific demographic indicators can be driven only if the purpose and scope of the analysis are clearly defined.

In this study, to improve the usability of the environmental analysis method (STEEP) among nonexperts, the selection criteria for indicators and data was established as follows: reducing the time and cost required to obtain and interpret data; ensuring publicness, objectivity, and accessibility of the data; and providing guidelines for non-experts to interpret the data and understand the relationships more easily.

Accordingly, as shown in [Fig. 2], the sub-factors were categorized and data for each area of STEEP were selected so that even non-experts can easily identify the necessary indicators and find relevant data by themselves. 


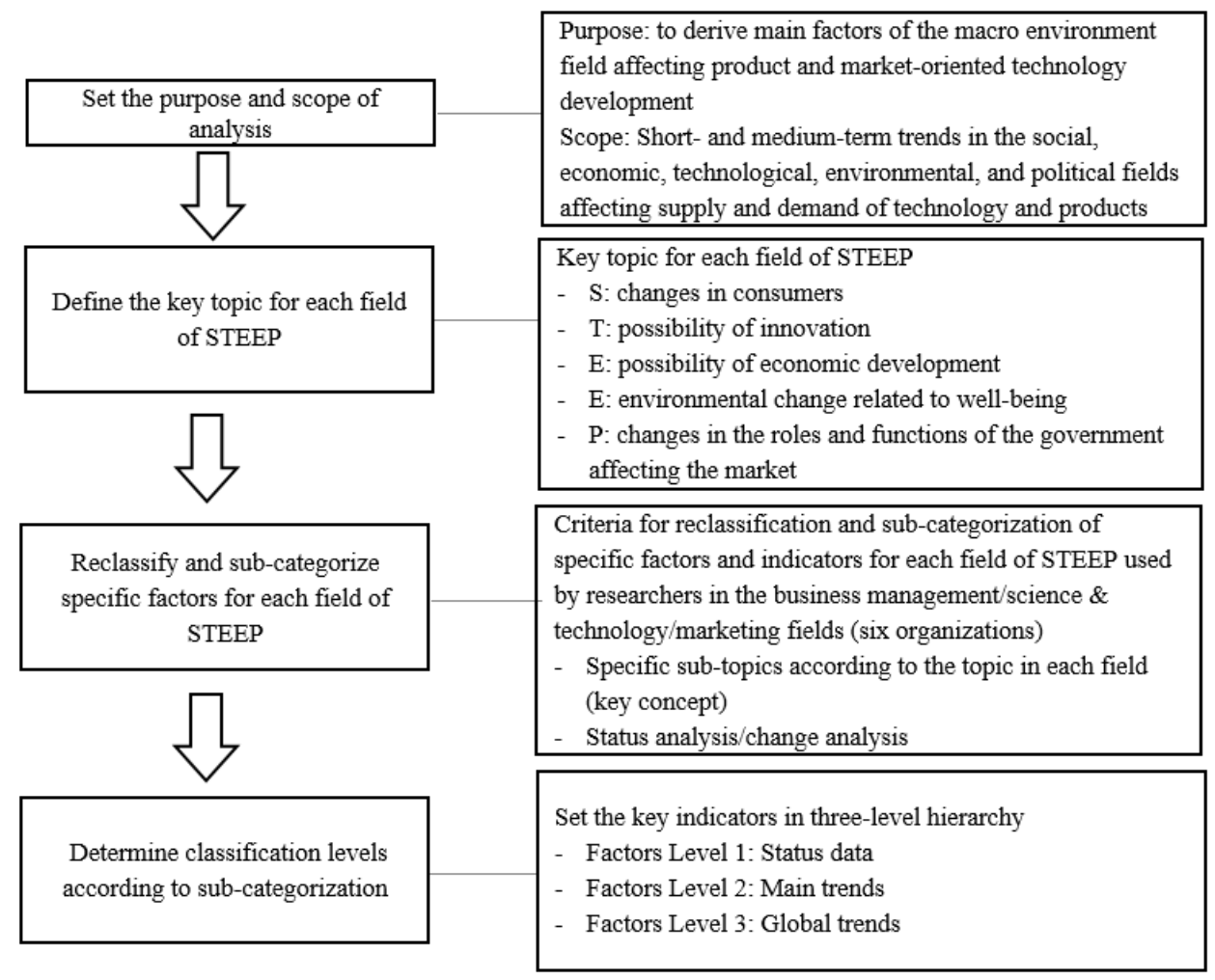

[Fig. 2] Process of Extracting Key Indicators for each STEEP Area

[Table 1] shows the classification criteria and description of indicators related to the main factors in each area of STEEP, defined according to the process outlined above.

[Table 1] STEEP Key Indicators Classification Criteria

\begin{tabular}{|c|c|c|c|c|}
\hline $\begin{array}{l}\text { Indicator } \\
\text { Group }\end{array}$ & $\begin{array}{c}\text { Classification } \\
\text { Criteria }\end{array}$ & Description & Data Type & Main Sources \\
\hline $\begin{array}{l}\text { Factors } \\
\text { Level } 1\end{array}$ & Status data & $\begin{array}{l}\text { Basic statistics related to } \\
\text { basic conditions and } \\
\text { structure formation in the } \\
\text { field }\end{array}$ & $\begin{array}{c}\text { Quantitative data, } \\
\text { statistics }\end{array}$ & $\begin{array}{c}\text { Statistics Korea, KISTEP Science \& } \\
\text { Technology Policy Support Service, } \\
\text { IITP, Korea Development Institute, } \\
\text { Institute of Foreign Affairs and National } \\
\text { Security (IFANS) }\end{array}$ \\
\hline $\begin{array}{l}\text { Factors } \\
\text { Level } 2\end{array}$ & Main trends & $\begin{array}{c}\text { Key to changes in each area } \\
\text { based on the Level-1 } \\
\text { indicators }\end{array}$ & $\begin{array}{l}\text { Qualitative data, } \\
\text { report, text }\end{array}$ & $\begin{array}{l}\text { Statistical Research Institute, Ministry of } \\
\text { Science and ICT, Korea Institute for } \\
\text { Industrial Economics \& Trade (KIET), } \\
\text { IFANS, Korea National Environmental } \\
\text { Technology Information Center } \\
\text { (KONETIC) }\end{array}$ \\
\hline $\begin{array}{l}\text { Factors } \\
\text { Level } 3\end{array}$ & Global trends & $\begin{array}{c}\text { Global-level main } \\
\text { information for Levels } 1 \text { and } \\
2\end{array}$ & $\begin{array}{c}\text { Qualitative/quantitative } \\
\text { data, report }\end{array}$ & $\begin{array}{c}\text { UN, World Bank, OECD, S\&T GPS } \\
\text { Global Science \& Technology Policy } \\
\text { Support Service, KIET, IFANS, } \\
\text { McKinsey Global Institute }\end{array}$ \\
\hline
\end{tabular}

\subsection{Supersystem Analysis: Extraction of Supersystem Elements Using Five Forces Analysis Method}

Porter's five forces, a very useful framework for analyzing competition among existing companies in the market, divides the business environment into different levels, and thus, indirectly analyzes the impact of macro environmental factors on companies by using the competitive forces of the industry to which a company belongs[12]. Competitive forces include industry rivalry, suppliers, buyers, 
substitutes, and new entrants in the traditional classification of economics and business management. In the field of marketing, they are defined as micro environmental factors-suppliers, resellers, customers, competitors, and the public[14]. Most importantly, five forces analysis seeks to predict the probability of survival and success of a company (or a product) in the market, and defines the factors with a direct impact on it.

For market-centered R\&D planning, the external environment is divided into Supersuper-system, a common macro environment, and Supersystem, a micro environmental factor that has a direct impact on the products in the markets, according to multi-screens, the systematic analysis method of TRIZ, and the interrelationship of the two systems is analyzed. The five aspects of the five forces analysis are applied to define the supersystem and its five factors (mentioned above) more precisely.

\section{Method and Tool for Analyzing the External Environment of Technical Systems}

\subsection{Method of Classifying STEEP factors for Supersuper-system Analysis}

In this study, the supersuper-system analysis method is intended to facilitate a systematic subcategorization of extensive conventional factors for each area of STEEP. This method is also useful for extracting necessary indicators, and understanding the relationships between the indicators. There are three steps to systematizing the classification of STEEP indicators. First, the purpose (market-oriented technology development) and analysis topic for each field of STEEP are established. Second, the contents for each of the social, technological, economic, environmental, and political areas (large category) are sub-categorized according to the analysis topic to define the key concepts (medium category) corresponding to the topic. Finally, the indicators used by six organizations in the fields of science \& technology, business management, and marketing [1][9-13] are classified in detail (small category) based on the key concepts. Based on this, [Table 2] shows the specific factors derived for each area of STEEP.

[Table 2] Classification of Sub-factors for Each Area of STEEP

\begin{tabular}{|c|c|c|c|}
\hline \multirow{2}{*}{$\begin{array}{l}\text { Large } \\
\text { Category }\end{array}$} & \multicolumn{2}{|r|}{ Medium Category } & Small Category \\
\hline & \multicolumn{2}{|r|}{ Key Concept } & Main Factors \\
\hline \multirow{3}{*}{ Social } & Level 1 & $\begin{array}{c}\text { Population (households) and } \\
\text { income structure status }\end{array}$ & $\begin{array}{l}\text { Main demographic (household) indicators, GNI per capita, household } \\
\text { consumption expenditures, total savings rate, ratio of women workers }\end{array}$ \\
\hline & Level 2 & $\begin{array}{l}\text { Changes in domestic } \\
\text { demographic and } \\
\text { consumption structures }\end{array}$ & $\begin{array}{l}\text { Population (household) projection analysis; household income and } \\
\text { consumption changes; generation classification, distinction, and } \\
\text { characteristics; digital life changes; list of changes in trendy products }\end{array}$ \\
\hline & Level 3 & $\begin{array}{l}\text { Changes in global } \\
\text { demographic and } \\
\text { consumption structures }\end{array}$ & $\begin{array}{l}\text { Population by country indicators, global population forecast, GNI per } \\
\text { capita in each country, global digital life changes }\end{array}$ \\
\hline \multirow{3}{*}{ Technological } & Level 1 & New technology trends & Emerging technologies, ICT issues \\
\hline & Level 2 & $\begin{array}{c}\text { R\&D policy changes of } \\
\text { government and companies }\end{array}$ & $\begin{array}{l}\text { R\&D investment, R\&D human resources, R\&D laws and bills, } \\
\text { technology industry support and regulation policies }\end{array}$ \\
\hline & Level 3 & Global R\&D policy changes & R\&D investment by country, R\&D policies by country \\
\hline \multirow{3}{*}{ Economic } & Level 1 & $\begin{array}{l}\text { Macroeconomic and } \\
\text { industrial status }\end{array}$ & $\begin{array}{l}\text { Main domestic and foreign macroeconomic indicators, analysis of } \\
\text { domestic and foreign economic trends, domestic and foreign } \\
\text { economic outlooks }\end{array}$ \\
\hline & Level 2 & $\begin{array}{l}\text { Industrial structure changes } \\
\text { and economic support } \\
\text { policies: regulatory changes }\end{array}$ & $\begin{array}{l}\text { National economic stimulation policies, new industry policies, } \\
\text { technology and industry regulation policies }\end{array}$ \\
\hline & Level 3 & $\begin{array}{l}\text { Changes in global economic } \\
\text { and industrial structures }\end{array}$ & Global industrial structure status, economic policies by country \\
\hline Environmental & Level 1 & Environmental issues & Resources, energy, climate change \\
\hline
\end{tabular}




\begin{tabular}{|c|c|c|c|}
\hline & Level 2 & $\begin{array}{c}\text { Changes in environmental } \\
\text { policies (support and } \\
\text { regulations) }\end{array}$ & Environmental regulatory laws \\
\hline & Level 3 & $\begin{array}{c}\text { Changes in global } \\
\text { environmental issues and } \\
\text { policies }\end{array}$ & Sustainable industry trends, global environmental regulations and laws \\
\hline \multirow{3}{*}{ Political } & Level 1 & Political status & Domestic and foreign political situations and trends \\
\hline & Level 2 & Domestic political trends & $\begin{array}{l}\text { Government state affairs (strategies and execution plans), } \\
\text { government's foreign policy changes }\end{array}$ \\
\hline & Level 3 & Global political trends & Global political issues, U.S.-China conflict, China's political situation \\
\hline
\end{tabular}

The classification system is characterized by the division of a range of factors and data into key concepts according to the hierarchical level. This guides users to easily find the factors, indicators, and data required for analyzing the external environment around key concepts. It is relatively easy to extract keywords around the main concepts from the literature to analyze the trend in each STEEP area.

To support this process, an external environmental analysis tool based on the TRIZ's multi-screens was developed. This tool allows researchers in science, technology, and engineering to perform STEEP analysis for examining the environment of a technical system easily and quickly.

\subsection{Tools for Analyzing the External Environment of Technical Systems}

\subsubsection{Supersuper-system Analysis Tool: STEEP Analysis Template}

The STEEP analysis template was developed to use the classified indicators by distinguishing the three levels of "status-main trends-global trends" based on quantitative and qualitative data. This template is designed to easily find the necessary data and data sources according to the key concepts of each area. It can also quickly identify the trend changes through the changes in the core keywords in STEEP, from the past to the present, thus enabling users to predict the future trends.

In this study, the trend in each STEEP area is analyzed around the Level 2 key concepts. There are two main methods for deriving trends. In the first method, users investigate the data of the main factors by key concepts to analyze the pattern of changes. In the second method, users extract core keywords from the existing literature that analyzes megatrends while considering duplicates, similarities, and relationships in the search results of the key concepts. For example, to analyze the trend in a social area, core keywords can be derived using the main indicators in Level 2, namely, population, household, consumption, generation, digital, and trendy products, as search words in the literature on megatrends [15], as shown in [Table 3].

[Table 3] Core Keywords for Main Indicators in Level 2 in Social Area

\begin{tabular}{|c|c|}
\hline Main Factors & Core Keywords for Short-term Future (1-5 Years) \\
\hline Future population projection & $\begin{array}{c}\text { Super-aging, increased need for elderly employment, the need for health and quality of life, } \\
\text { increased demand for medical and healthcare technology, ultra-low birth rate, decreased } \\
\text { school-age/youth population, worsening of imbalance between age groups, worker scarcity } \\
\text { and declining productivity, imbalance in supply and demand of labor, increased migration } \\
\text { between countries, use of bioengineering technology, increase in urban population, demand } \\
\text { for smart cities, mega-urbanization }\end{array}$ \\
\hline Future household projection & $\begin{array}{c}\text { Single-person household, increased percentage of married-couple households, } \\
\text { diversification of household composition, small household size, aging of single-person } \\
\text { householders, family value change, multi-culturalism, women's social advancement }\end{array}$ \\
\hline
\end{tabular}




\begin{tabular}{|c|c|c|}
\hline $\begin{array}{c}\text { Household income/consumption } \\
\text { change }\end{array}$ & $\begin{array}{c}\text { Income polarization, worsening income disparity, worsening imbalance of income and } \\
\text { employment, worsening conflict between social classes, online shopping, rational } \\
\text { consumption, consumption sharing, digital platform, electronically mediated workers, gig } \\
\text { economy, digital goods, online to offline, on-demand economy, value-oriented } \\
\text { consumption, MEconomy (Me+Economy), Gen MZ consumers, intelligent consumption, } \\
\text { remote consumption, focusing on high-class workers, job polarization }\end{array}$ \\
\hline $\begin{array}{c}\text { Distinction and characteristics } \\
\text { of generations }\end{array}$ & $\begin{array}{c}\text { Value diversification, generation conflict, worsening of social conflicts, diversification in } \\
\text { generation composition, digital gap, emergence of new consumption generation/mobile } \\
\text { new human species, YOLD (Young Old) generation, Generation MZ (places importance on } \\
\text { individualism, empiricism, realism, and diversity) }\end{array}$ \\
\hline $\begin{array}{c}\text { Digital life change } \\
\text { Online shopping, remoteness, spread of telecommuting, digital social evolution, } \\
\text { acceleration of a contact-free society, platform service use acceleration, social gaps and } \\
\text { conflicts due to digital gaps, digital literacy, unstaffed, automation, sharing economy, } \\
\text { various values, digital and non-face-to-face communication, digital-twin urban space, } \\
\text { digital goods, digital currency, surrealization, real-time contents, digital bank, blockchain, } \\
\text { TechFin, multiple digital identities, digital healthcare, digital smart city }\end{array}$ \\
\hline Trendy product change & \begin{tabular}{c} 
Streaming service \\
\hline
\end{tabular} \\
\hline
\end{tabular}

A statistical analysis of the content derived from the key trends in Level 2 can use quantitative data from Level 1, and an analysis to predict a trend's global dimensions can use Level 3 data.

By summarizing the analysis at different levels, a STEEP analysis template is composed based on the keywords of each area, as shown in [Table 4].

[Table 4] STEEP Analysis Template (Social Area)

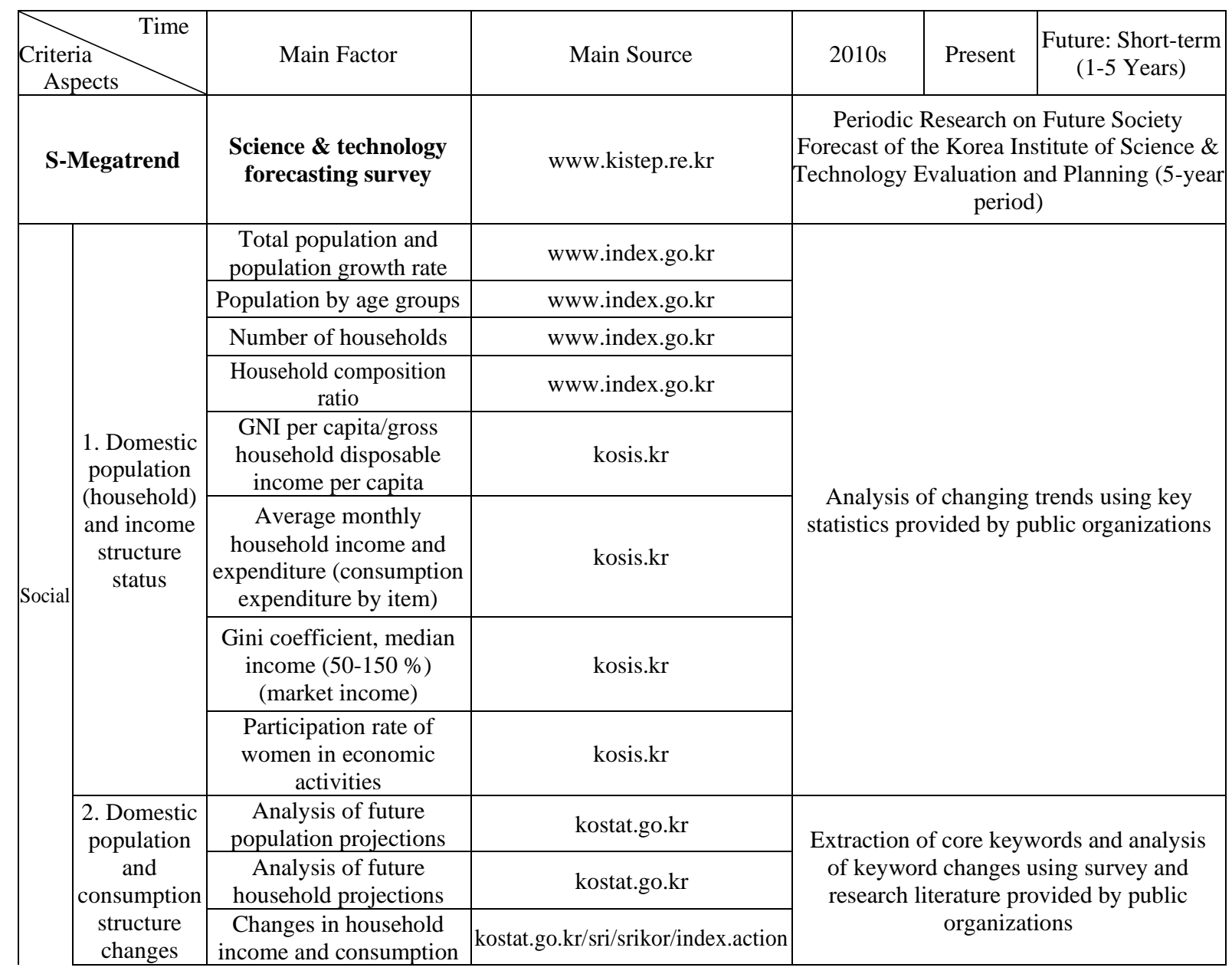




\begin{tabular}{|c|c|c|c|}
\hline & $\begin{array}{c}\text { Classification and } \\
\text { characteristics of each } \\
\text { generation }\end{array}$ & kostat.go.kr/sri/srikor/index.action & \\
\hline & Changes in digital life & www.index.go.kr/main.do & \\
\hline & $\begin{array}{c}\text { Changes in trendy } \\
\text { products }\end{array}$ & $\begin{array}{c}\text { Consumer Trend Center, Seoul } \\
\text { National University }\end{array}$ & \\
\hline \multirow{4}{*}{$\begin{array}{l}\text { 3. Global } \\
\text { population } \\
\text { and } \\
\text { consumption } \\
\text { structure } \\
\text { changes } \\
\end{array}$} & $\begin{array}{l}\text { Changes in global } \\
\text { population structure }\end{array}$ & population.un.org/wpp/Publications & \multirow{4}{*}{$\begin{array}{l}\text { Extraction of core keywords and analysis of } \\
\text { keyword changes based on literature and } \\
\text { statistical data provided by public } \\
\text { organizations }\end{array}$} \\
\hline & \multirow{3}{*}{$\begin{array}{l}\text { Changes in global } \\
\text { consumption structure }\end{array}$} & databank.worldbank.org & \\
\hline & & www.itu.int/en/Pages/default.aspx & \\
\hline & & www.mckinsey.com/mgi/overview & \\
\hline
\end{tabular}

The keywords extracted by area, repeatedly appearing across the STEEP areas, include polarization, imbalance, deepening conflicts, individualization, connectivity, diversification, smartification, remoteness, digital economy, platform service, circular economy, and reorganization of the traditional global value chain. Based on this finding, researchers forecast the overall macro external environment trends for the near future.

\subsubsection{Supersystem Analysis Template}

The key to the supersystem analysis of a technical system is to identify the relationships between each STEEP factor and the five supersystems that have a direct impact on the survival or success of a product or technology in the market. This analysis is done by using the core keywords in STEEP. These relationships define the external environmental factors that affect the future development of the technical system. The supersystem analysis template was developed as a tool for conducting this analysis.

The supersystem analysis template is designed to systematically analyze the impact of the key trends in each area of STEEP on each of the five forces of the micro environmental factors. An example of a social area is shown in [Table 5].

[Table 5] Supersystem Analysis Template (Social Area)

\begin{tabular}{|c|c|c|c|c|c|c|}
\hline \multicolumn{2}{|c|}{ Forces } & \multicolumn{5}{|c|}{ STEEP Factors-Short-term } \\
\hline Category & $\begin{array}{l}\text { Target and } \\
\text { Charact- } \\
\text { eristics }\end{array}$ & Field & Factor Group & Main Factor & $\begin{array}{c}\text { Core } \\
\text { Keyword }\end{array}$ & $\begin{array}{c}\text { Impact of Factor } \\
\text { (Description) and } \\
\text { Strategy }\end{array}$ \\
\hline \multirow{10}{*}{$\begin{array}{c}\text { Suppliers/ } \\
\text { Consumers/ } \\
\text { Substitutes/ } \\
\text { Competitors/ } \\
\text { New } \\
\text { Entrants }\end{array}$} & & \multirow{10}{*}{ Social } & \multirow{8}{*}{$\begin{array}{l}\text { L-1 Domestic } \\
\text { population } \\
\text { (households) } \\
\text { and income } \\
\text { structure } \\
\text { status }\end{array}$} & $\begin{array}{l}\text { Total population and } \\
\text { population growth rate }\end{array}$ & & \\
\hline & & & & $\begin{array}{l}\text { Population (ratio) by age } \\
\text { groups }\end{array}$ & & \\
\hline & & & & $\begin{array}{l}\text { Number of households } \\
\text { (increase rate) }\end{array}$ & & \\
\hline & & & & $\begin{array}{l}\text { Household composition } \\
\text { ratio by generation }\end{array}$ & & \\
\hline & & & & $\begin{array}{c}\text { GNI per capita/ } \\
\text { Gross household disposable } \\
\text { income per capita }\end{array}$ & & \\
\hline & & & & $\begin{array}{l}\text { Average monthly household } \\
\text { income and expenditure }\end{array}$ & & \\
\hline & & & & $\begin{array}{l}\text { Median income (50-150\%, } \\
\text { market income) }\end{array}$ & & \\
\hline & & & & $\begin{array}{l}\text { Participation rate of women } \\
\text { in economic activities }\end{array}$ & & \\
\hline & & & \multirow{2}{*}{$\begin{array}{l}\text { L-2 Changes } \\
\text { in domestic } \\
\text { populations } \\
\text { and }\end{array}$} & $\begin{array}{c}\text { Analysis of future } \\
\text { population projections }\end{array}$ & & \\
\hline & & & & $\begin{array}{c}\text { Analysis of future } \\
\text { household projections }\end{array}$ & & \\
\hline
\end{tabular}




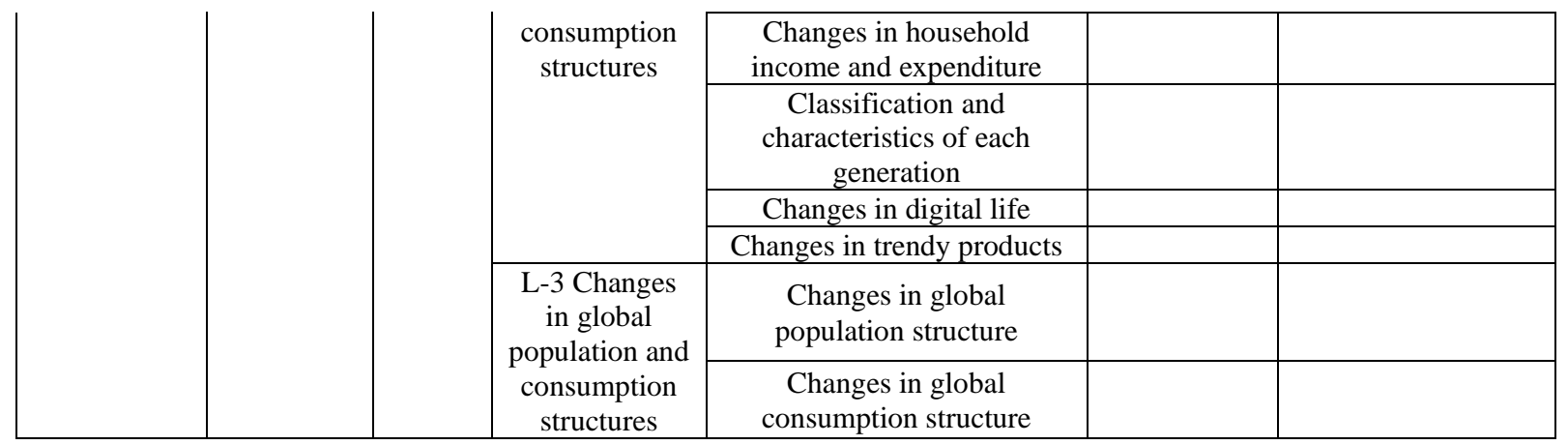

Users can specify the five supersystems of a given system and identify their impact on it, as well as understand the relationship with core keywords by the level in each area specified in the STEEP analysis template. The frequency of the words related to the core keywords in each STEEP area indicates the degree of impact on the system.

\section{Conclusions}

A practical external environmental analysis method and tools based on TRIZ's multi-screens were developed that can be easily used by science, technology, and engineering researchers and researchers from small- and medium-sized companies to establish their R\&D strategies for product development.

The tool was used to divide the external environmental factors of the technical system into macro environmental factors (supersuper-systems) and micro environmental factors (supersystems). By using the STEEP method, the trends and core keywords for the five macrosystems were derived. The five microsystems were defined by applying the five forces analysis method. Also, a guideline was provided to analyze the impact of the main factors of social, technological, economic, environmental, and political areas on the supersystem by using the STEEP and the supersystem analysis templates.

[Fig. 3] summarizes the prediction method for technical systems based on TRIZ's multi-screens method.

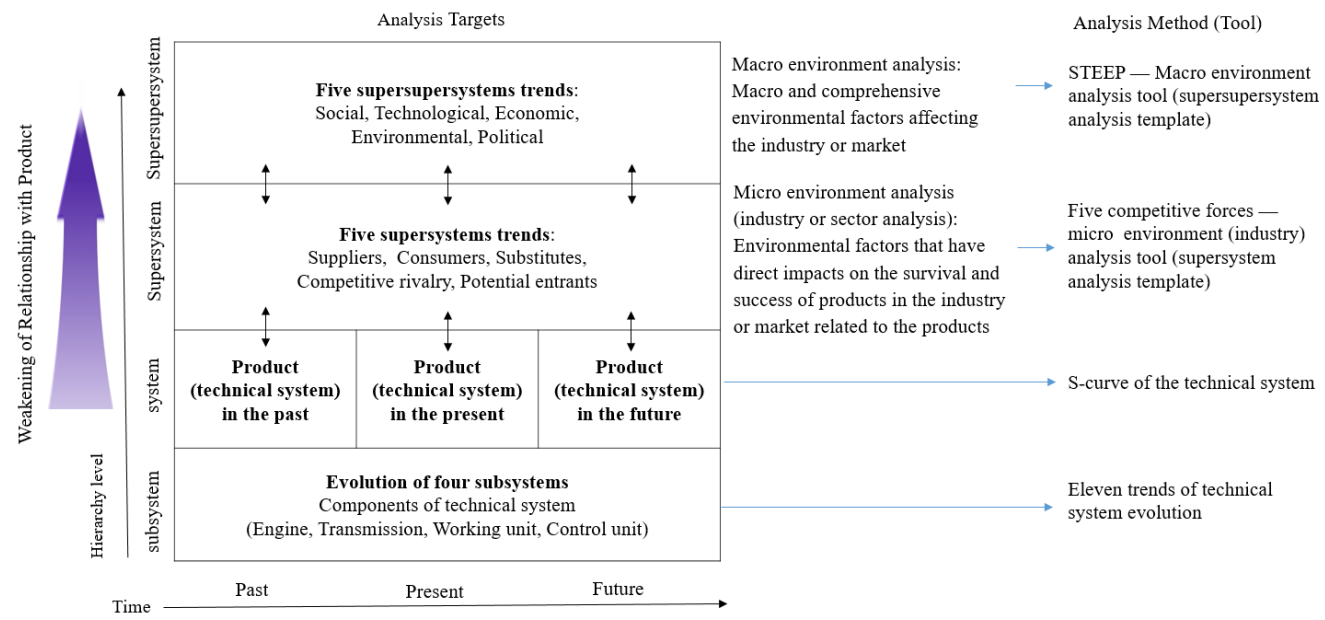

[Fig. 3] Future Prediction Method for Technical Systems Using Multi-screens System Operator

It is expected that the external environmental analysis tool will be used to define external environmental factors that significantly affect the technical system of the R\&D planning and development. This study provides a theoretical basis for developing a convenient external environmental analysis method and tool to use in the market-oriented technology R\&D field. Case studies are needed to analyze their accuracy and appropriateness in predicting future technology development and 
establishing R\&D strategies. Therefore, a follow-up study is needed to verify this assumption by applying the tools to specific technical systems and deriving future prediction results.

\section{Acknowledgments}

This research was supported by the Basic Science Research Program through the National Research Foundation of Korea (NRF) funded by the Ministry of Education (2018R1D1A1B07049244).

\section{References}

[1] Global Future Studies Association, The Strategic Methodology for Futures Studies, Dunam, pp.91-168, (2014)

[2] Y. W. Song, Analysis of Technology Evolution Trends for Predicting Future Technologies, Asia-Pacific Journal of Convergent Research Interchange, (2020), Vol.6, No.10, pp.123-136, DOI: http://dx.doi.org/10.47116/ apjcri.2020.10.10

[3] H. S. Chang, W. J. Choi, H. S. Tho, A Study on Establishment of National Science and Technology Strategy Applying PEST-SWOT-AHP: A Case Study of Fusing R\&D, Journal of Korea Technology Innovation Society, (2012), Vol.15, No.4, pp.766-782, UCI: G704-001043.2012.15.4.007

[4] H. M. Kim, J. H. Han, Y. B. Kim, Study on Future Foresight of the Technology Commercialization Policy, Journal of Industrial Economics and Business, (2013), Vol.26, No.2, pp.803-824, UCI: G704-001438.2013.26.2.011

[5] H. B. Park, A Study on Domestic Demand on OTT Service by Using Three Dimensional Forecasting. Korea Advanced Institute of Science and Technology, Master's thesis, pp.8-13, (2017)

[6] S. Y. An, S. Lee, J. J. Yoon, S. Y. Kim, H. Ju, S. Kim, Future Residential Forecasting and Recommendations of Housing Using STEEP-V Analysis, The Journal of the Korea Contents Association, (2020), Vol.20, No.6, pp.230-240, DOI: https://doi.org/10.5392/JKCA.2020.20.06.230

[7] G. S. Altshuller, Creativity as an Exact Science, CRC Press, pp.94-98, (2006)

[8] S. Ikovenko, M. Przymusiala, S. Yatsunenko, M. C. Barkan, P. Karendal, S. Kobyakov, J. Obojski, Z. Vintman, Theory of Inventive Problem Solving - State of the Art, Novismo, pp.136-140, (2019)

[9] B. E. Bensoussan, C. S. Fleisher, Analysis without Paralysis, Pearson, pp.187-197, (2013)

[10] https://stepi.re.kr/site/csfko/main.do, Dec 29 (2021)

[11] https://blog.oxfordcollegeofmarketing.com/2016/06/30/pestel-analysis, Dec 29 (2021)

[12] G. Johnson, R. Whittington, K. Scholes, D. Angwin, P. Reger, Exploring Strategy, Pearson, pp.32-95, (2017)

[13] https://rapidbi.com/the-pestle-analysis-tool, Dec 29 (2021)

[14]https://blog.oxfordcollegeofmarketing.com/2014/11/04/the-impact-of-micro-and-macro-environment-factors-onmarketing, Dec 29 (2021)

[15] E. S. Jeong, the 6th Science and Technology Forecast Survey Research (First Year), Korea Institute of Science \& Technology Evaluation and Planning, pp.13-42, (2021) 